\title{
An Examination of the Economics of Sustainable and Conventional Horticulture
}

\author{
Robin G. Brumfield ${ }^{1}$
}

\begin{abstract}
AdDITIONAL INDEX WORDS. costs and returns, alternative agriculture, organic agriculture

SummarY. Since World War II, U .S. agriculture has reduced production costs by substituting petrochemicals for labor. Adverse impacts from chemical intensive agriculture include increased pest levels, groundwater and surface water contamination, soil erosion, and concerns about harmful levels of pesticide residues. Sustainable farming programs such as integrated crop management (ICM) and organic farming encourage farmers to use systems that reduce the adverse impacts of chemical agriculture. H owever, before farmers adopt an alternative system, they must determine that economic benefits from the alternative farming activities exceed the costs incurred. U nfortunately, relatively few studies have compared the cost of organic crop production with conventional production systems. R esults of these studies are mixed. In some studies, organic systems are more profitable than conventional systems with organic price premiums, but are not economically viable without price premiums. In one long-term study, the organic system was more profitable than a conventional one if the cost of family labor was ignored, but less profitable if it was included. In some studies, net returns were higher for ICM than for conventional or organic systems, but in others, they were higher. R esults also vary on a crop by crop basis.
\end{abstract}

A $t$ the beginning of the 20th Century, the $U$ nited States was primarily an agrarian society. After World War II, however, agriculture followed the rest of the U.S. economy and adopted an industrial workplace model (I kerd, 1996). The industrial model reduced the cost of production through economic incentives that incorporated economies of scale, comparative advantage, opportunity costs, specialization, automation, and simplification into work activities. These concepts provided a focus for the U.S. land grant system where researchers, producers, and agricultural support industries worked to increase productivity and reduce costs. U .S. agricultural productivity increased dramatically. In 1940, 17\% of the population was engaged in agricultural production. Today, less than $2 \%$ of the U.S. population works in agriculture and less than $10 \%$ of our disposable income is spent on food.

Department of Agricultural, Food, and Resource Economics, Rutgers, The State U niversity of N ew Jersey, 55 Dudley Road, N ew Brunswick, NJ 08901-8520.

The cost of publishing this paper was defrayed in part by the payment of page charges. U nder postal regulations, this paper therefore must be hereby marked advertisement solely to indicate this fact.

${ }^{1}$ Specialist in farm management. 
A verage U .S. farm size increased from 168 acres (68 ha) in 1990 to 487 acres(197 ha) by 1997 (U SD A, 2000). U nited States agricultural productivity increased dramatically because of increased mechanization, new technologies, increased chemical and fertilizer use, and specialization. G overnment policies have also favored this shift toward maximizing production.

The industrialization of agriculture and the development of synthetic chemicals and fertilizers allowed farmers to increase yields and reduce risks. Theseincreased yieldsresulted in lower per-unit costs (Brumfield, 1996). Although increased yieldsarea ben efit to both producers and consumers, several disadvantages have resulted from the use of agricultural chemicals. As farmers increased rates and frequency of application of chemicals, target insects have developed resistance to particular chemicals, and some pest populations have increased dramatically (National Research Council, 1986; Office of Technology Assessment, 1995). O ther unintended costs of industrial agriculture include topsoil depletion, groundwater contamination (U.S. General Accounting Office, 1991), damage to wildlife (Lichtenberg, 1992), decline in the number of family farms, erosion of rural community economies (Feenstra et al., 1996), applicator health risks (Lichtenberg, 1992), and concerns about chemical residues in foods ( $\mathrm{H}$ anson et al., 1990; Lichtenberg, 1992).

In the late 1970 sand early 1980 s, environmental concerns spurred authors such as H odges $(1978,1982)$ to endorse organic agriculture asan alternative to pesticide-based agriculture. In the popular press, authors such as Rachel Carson (1962), and later, Wendell Berry (1981, 1984, 1986) criticized the widespread use of agricultural chemicals, the industrialization of agriculture, and the sociological impacts of post-W orld War II agricultural methods. M any people began to believe that the price we pay for food does not reflect all the costs of production (I kerd, 1990, 1996). By the 1980s, a host of systems including low input agriculture, alternative agriculture, integrated pest management, integrated crop management, biodynamic agriculture, agroecology, regenerative agriculture, and organic agriculture were proposed as alternatives to conventional agriculture. U Itimately, sustainable agriculture became theterm used in policy areas related to questions of the environment and resource conservation and the term organic was used in the marketplace as a label to differentiate among agricultural commodities (Klonsky and Tourte, 1998). E colabling has gained widespread acceptance in Western Europe, and initiatives have begun in Virginia and $\mathrm{N}$ ew York in the $\mathrm{U}$ nited States. Eco-labels are used to differentiate products that are produced using sustainable production practices such asI PM and low-inputagriculture(Estes et al., 1999).

The organic movement emphasized the relationship between agriculture and resource conservation by emphasizing the limited use of nonrenewable reso urces. Regulation of agricultural methods that focus on natural systemsand ecological processes is difficult to accomplish because these methodsoften areconceptual and open to interpretation. Thus regulation of organic production became a list of acceptable and unacceptable inputs (Klonsky and Tourte, 1998), with most states having certification programs for organically certified products. Certification assures consumers that the product was produced using organic methods and assures producers that theterm organic isnot used unscrupulously (Lohr, 1998). To avoid farming by neglect or the overuse of organic chemicals, the O rganic FoodsProduction Act of 1990 requires farm plans.

Sustainable agriculture is a new paradigm in which farmers and consumers recognize unintended side effects are likely through some production practices. Scaller's 1988 article in A gricultural Outlook compared alternativeand conventional agriculture and explained the increased public attention paid to alternative agriculture. $\mathrm{He}$ listed factors that would affect the adoption of alternative agriculture: commodity and input prices, farm and environmental policies, infrastructure and markets, transition, and research and education. With initial appropriation in 1987, Low Input Sustainable Agriculture (LISA) was U SDA's research and education grants program. The 1990 Farm Bill expanded the program and subsequently renamed it the Sustainable Agriculture Research and Education (SARE) program. The $1990 \mathrm{Farm}$ Bill defined the term sus- tainable agriculture to mean an integrated system of plant and animal production practices having a site-specific application that will over thelong term: satisfy human food and fiber needs; enhanceenvironmental quality and the natural resource base upon which the agricultural economy depends; make themost efficient use of nonrenewable resources and on-farm resources and integrate, where appropriate, natural biological cycles and controls; sustain the economic viability of farm operations; and enhance the quality of life for farmers and society as a whole (G overnment Printing O ffice, 1990).

Economists have proposed various approaches to paying for unintended costs of chemical based agriculture. Lichtenberg (1992) proposed three alternatives to regulation: liability, information, and taxes. Lichtenberg concluded that liability already was being used for pesticide regulation for poor product performance. H owever, it becomes a poor policy instrument when environmental damage or health and safety issues are concerned, and it is costly. $\mathrm{H}$ e concluded that information would be most effective in the area of farm worker safety. Taxes tend to influence application rates on a continuous basis, but cannot alter timing of applications. Abler (1992) favored market-based solutionsto unintended side effects of chemical agriculture. People can refuse to work with pesticides that they view as unsafe, farmers can refuse to buy unsafe pesticides, and consumers can refuse to buy produce they perceive as unsafe. Farmers would use safer chemicals, and competition would force reductions in per unit prices, which would be passed along to consumers. H arper (1992) argued that in developing policy tools to account for unintended negative side effects of pesticide use, both individual risks and aggregate health risks should be taken into account. She stated that both benefits and risks of pesticides are overestimated. She also proposed develo ping models that take into account technological changeand economic adoption if and when pesticides are no longer freely available or acceptable to consumers. It appears that a combination of policy tools is likely to be used.

O rganic food sales are only $1 \%$ to $1.5 \%$ of retail food sales (Raterman, 1997). O rganic production methods are used on less than $1 \%$ of farms and 
$1 \%$ of farmland engaged in U.S. vegetable production (Klonsky and Tourte, 1998). H owever, the emergence of organic agriculture represents a much larger impact on the paradigm shift from industrial agriculture to a new moresustainable agriculture (Darling, 1991). The principles of sustainable agriculture are increasingly being incorporated into conventional agriculture. Integrated crop management, an ecologically based approach to crop production that includes management practices such as minimum tillage, nutrient balancing, and integrated pest management (IPM), has been widely adapted by producers. $M$ any farmers rotate crops, apply fertilizers in bands, mulch, stake and use other practices that reduce their dependence on synthetic chemicals to produce high quality crops. After four decades of chemically dependant agricultural research, land grant universities are now doing research on sustainable agriculture, and chemical companies are introducing pesticides, fungicides, and herbicides which are less toxic and more environmentally benign ( $D$ arling, 1991). Producersarefinding that diversified farms arelesseconomically and environmentally risky (C acek and L angner, 1986). Growing a large number of crops spreads the economic and production risks and makes the farm less susceptible to changes in supply and demand for a specific crop ( $\mathrm{H}$ arwood et al., 1999). Farm bills since 1985 have included funding for research and extension programs that develop more sustainable systems. As farmers becomemoreaware of thelong-run costs of over dependence on petrochemicals and fertilizers, and consumers continue to push for a safer environment and safer food, both regulations and the marketplace will encourage farmers to adopt more sustainable systems.

The organic movement not only changed production, but also has had impacts on marketing. For example, Community Supported Agriculture (CSA) is a partnership-marketing venture between organic farmers and consumers. CSAs represent a shift from the individualism of traditional agriculture to a community approach to producing food; they also represent a channel through which organic produce can be distributed. CSAs depend on a direct link between local producers and the local community. The CSA sells individual shares in the farm before the planting season, thus giving the CSA an infusion of equity to purchase inputswithout having to finance the operation through credit. In turn, the shareholders receive bags of produce from the CSA throughout the growing season. CSAs often include consumersin the decision-making processes of what produce to grow, how to market, and whether labor as well as financial support is required by shareholders. Purchasing produce from a CSA requires more of a consumer's time than buying from a supermarket. This concept began in Japan in the 1960s where it was called "teikei," which means "putting the farmer's face on food" (Van En et al., 1999). The idea traveled to Europe and was introduced to the U.S. in 1985 by J an VanderTuin at Indian Line Farm in Great Barrington, M assachusetts (Sabih and Baker, 2000). T oday, there are over 1,000 CSAs in the US and $C$ anada, mostly near urban areas. CSAs shift some of the production, market, and financial risk from producers to consumers. A studyby Sabih and Baker (2000) showed that CSAs gave farmers a bigger share of returns and give consumers lower costs than conventional agriculture. Farmers were able to realize substantially more income than with traditional techniques. The savings that consumers realized on groceriesyiel ded a return of $39 \%$ which washigher than alternativeinvestment opportunities.

Sustainable agriculture must be economically viableif it isto beadopted by producers. $M$ any producersareconcerned that while switching to organic or ICM methods would be more environmentally sustainable, it could be unprofitable and risky (Williams, 1990). Very few studies have been conducted which compare the economics of sustainable production systems to conventional ones. Studies relating to sustainableagricultural practices often contain no economic analysis(G leason etal., 1992; T emple, 1991) or they focus only on one crop (Baldwin, 1991; King, 1991). A 1997 Cornell study (Pritts and Kovach, 1997), compared break-even prices for conventional and organic strawberries (Fragaria xananassa Duchesne). The labor for weed control was twice as high in the organic system, and theyieldswere $30 \%$ to $70 \%$ lower. Break even prices were 34\% higher for organic strawberries than for conventional strawberries. A study comparing fresh produce prices over a 15-month period in North Carolina found, on average, about a $25 \%$ price premium for certified organic produce (Estes et al., 1999).

O nly limited attempts have been made to analyze the economics of whole farm sustainable systems (Dhillon and Paladino, 1981; Goldstein and Young, 1987; L ockertz, 1989). Studiessuch as that of Buttel et al. (1986) began to compare organic and conventional agriculture in ways that assessed not only the bottom line in terms of profits, but also in terms of the effects on the sustainability of family farms. Ray et al., (1992) reviewed previous research into alternative agricultural practices and discussed some of the limitations of research. They found the studies to be constrained by lack of reliable cost and return data. Fox et al. (1991) reviewed the literature published between 1975 and 1989 on the economics of alternative agricultural systems. All the studies used budgeting or linear programming, and much of the data was based on only 1 or 2 years. They found no general pattern about the relative profitability of alternative or conventional systems.

In a review of several farm-level studiescomparing sustainableand conventional cropping systems, L ee (1992) found that net returns and yields per acre tended to belower for sustainable cropping systems, but net returnscould be comparable under certain conditions. Smolik et al. (1995) found an alternative row cropping system to be more profitable than a ridge and till system in South D akota. M adden and O'Connell (1990) found that many farmerswho adopted sustainablemethods experienced a slight decrease in gross returns, but an increase in net returns. Dobbs et al. (1991) found that in side by side comparison of a conventional and alternativegrain farm, costs, gross returns, and net returns were higher and labor requirements were lower on the conventional farm than the alternative farm with no price premiums. Price premiumsfor organic products could have reduced or eliminated the difference in net returns. Later studies by D obbs (1994) found organic farms to be competitive with conventional and reduced tillage farms. In another study D obbs (1994) found profitability to be crop dependent. 
Conventional systemsweremore profitable than organic or near-organic systems in corn-soybean areas, and organic and near-organic were economically competitive in wheat areas.

The U niversity of California at $D$ avisbegan aresearch project to study conventional, low input, and organic farming systems. This research consisted of 2- to 5-year field studies to develop cost and return studies for over 125 crops. The budgetsincluded a wide range of fruits and vegetables and are available on line as well as in printed form. (Klonsky and Tourte, 2000; Klonsky, personal communication). O rganic price premiums ranging from $7 \%$ to $125 \%$ existed for all organic crops in the project. The organic system relied on price premiums for economic viability, except for beans (Phaseolus vulgaris L.), which were profitable even without the price premium. With price premiums, the organic system had the highest net returns, but without price premiums, it showed an average net loss. O n average, thelow input system outperformed the organic system without price premiums, but had higher costs, lower gross returns, and lower net returns than the conventional system. In general, the low input system showed potential to decrease the costs of chemical inputs and to maintain gross returns in comparison to the conventional system, but thisvaried with some crops. Yields of low input tomatoes (Lycopersicon esculentum Mill.) were similar to yields of conventional beans, but yields of low input corn (Zea mays L.) and beans were higher than with conventional production. O rganic premiums appear to be required for profitability. With price premiums, the organic system was the most profitable.

In longer-term studies, sustainable systems seem to fare better than conventional systems, depending on the assumptions and how costs are calculated. $\mathrm{H}$ anson et al. (1995) compared a conventional and organic rotational system in an on-going farming systems trial at the Rodale Institute Research Center in Kutztown, $\mathrm{Pa}$. They constructed budgets for three 5-year time periods. During the two later timeperiods, theyields of organic corn and soybeans (Glycine max. L. M err.) were comparable to yields in conventional systems. H owever, the organic systems produced higher-value crops lessfrequently, and required morefam- ily labor and management. I $f$ the value of family labor and management and the initial cost of investing in soil capital wereignored, organic rotationswere more profitable than conventional ones, but if those costs are included, the conventional system wasmoreprofitable. The organic system was adjusted asmoreinformation waslearned about sustainable systems. $\mathrm{H}$ anson et al. (1990) found that the sustainable system was more profitable on average after the initial 5-year transitional period. In a study comparing tomatoes produced using conventional, IPM , and organic systems by B rumfield et al. (1995), the yieldswerelower under an organic system. H owever, because of an organic price premium of $30 \%$ net returns per unit were higher under the organic system. The costs per acre were highest in the organic system, and the system changed as more information was learned about organic systems. The net returns per acre were highest for the IPM system. These results seem to indicate that costs will decline as organic systems are developed.

The principles of sustainable agricultureareincreasingly being incorporated into conventional agriculture. Producersmust be convinced that sustainable systems are profitable before they will adopt them. Differences in costs and returns of conventional, organic, and sustainable production systems vary with crop and assumptions made. I n general, organic systems rely on price premiums for economic viability. If producersare going to adopt more sustainable systems, more research is needed to develop systems and reduce costs of organic and ICM systems. M ethodsthat includethetrue costs of production, including family labor and unintended negative side effects, need to be developed. Policy tools that can account for these costs include regulations, liability, information, taxes, risk-benefit models, and market-based solutions.

\section{Literature cited}

Abler, D.G. 1992. I ssuesin pesticide policy: Discussion. N.E. J. Agr. Resource Econ. 19(2):93-92.

Baldwin, F.L. 1991. D eveloping and extending minimum input strategiesfor weed control in agronomic and horticultural crops. U niv. Ark. Coop. Ext. Sustainable Agr. Res. Educ. Rpt. LS88-11.
Berry, W. 1981. The gift of the good land. N orth Point Press, San Francisco, Calif:

Berry, W. 1984. The agricultural crisis as a crisis of culture, p. 219-225 In: G.K. D ouglas (ed.). Agricultural sustainability in a changing world order. Westview Press, Boulder, Colo.

Berry, W. 1986. Theunsettling of A merica: Cultureand agriculture. SierraClub Books, San Francisco, Calif.

Brumfield, R.G., F.E. Adelaja, and S. Reiners. 1995. E conomic analysis of three tomato production systems. Acta $\mathrm{H}$ ort. 340:255-260.

Brumfield, R.G. 1996. Sustainable horticulture: An overview. H ortT echnology 6(4):352-354.

Buttel, F.H ., G.W. Gillespie, J r., R. Janke, B. Caldwell, and M. Sarrantonio. 1986. Reduced-input agricultural systems: Rational and prospects. Amer. J. Alternative Agr. 1(2):58-64.

Cacek, T. and L.L. Langner. 1986. The economic implications of organic farming. Amer. J. Alternative Agr. 1(1):25-29.

C arson, R. 1962. Silent spring. H oughton Mifflin, Boston.

D arling, D.R. 1991. Research and education in the western region, p. 158-160. In: $\mathrm{N}$ ational Research Council. Board on Agriculture (eds.). Sustainable agriculture research and education in the field: A proceedings. N atl. A cad. Press, Wash., D.C.

Dhillon, P.S. and B.A. Paladino. 1981. $C$ haracteristics of organic vegetable farms in $\mathrm{New}$ Jersey with estimated costs and returns for selected organic crops. Cook College-RutgerstheStateU niv. N.J . Agr. Expt. Sta. Publ. 381.

D obbs, T.L. 1994. O rganic, conventional, and reduced till farming systems: Profitability in the Northern Great Plains. Choices, 2nd Q uarter. p. 31-32.

D obbs, T.L., J.D. Smolik, and C. M ends. 1991. O n-farm research comparing conventional and low-input sustainable agriculturesystemsin the northern $G$ reat Plains, p. 250-265. In: N ational Research Council Board on Agriculture (eds.). Sustainable Agriculture research and education in thefield: A proceedings. N atl. Acad. Press, Wash., D.C.

Estes, E.A., T. Kleese, L. Lauffer, D. Treadwell, and R. Burton. 1999. An overview of the $\mathrm{N}$ orth $\mathrm{C}$ arolina organic industry. ARE Rpt. 17, N.C. Agr. Res. Serv., N.C. State U niv., Raleigh.

Feenstra, G., C. Ingels, and D. C ampbell. with contributions from $D$. C haney, M . R. G eorge, E. Bradford, the staff and advisory committees of the $U$ niv. Calif. Sustainable 
Agriculture Research and Education Program (SAREP). 1996. What is sustainable agriculture? 16 July 2000. <http:// ww w.pen pages.psu.edu/ penpages reference/ $12101 /$ $121011083 . \overline{\mathrm{HTML}}$ >.

Fox, G., A. Weersink, G. Sarwar, S. D uff, and B. D een. 1991. Comparative economics of alternative agricultural production systems. N.E. J. Agr. Resource Econ. 20:124-142.

Gleason, M.L., S.E. Taylor, H.G. Taber, and M.L. H ockmuth. 1992. Timing of fungicide sprays on processing tomatoes. Fungicide N ematicide T ests 47:144.

Goldstein, W. A. and D. L. Young. 1987. Agronomic and economic comparison of conventional and a low-input cropping system in the Palouse. Amer. J. Alternative Agr. 2:51-56.

Government Printing O ffice. 1990. Food, Agriculture, Conservation, and Trade Act of 1990 (FACTA), Public Law 101-624, TitleXVI, SubtitleA, Section 1603. Govt. Printing O ffice, N AL KF 1692.A31, Wash., D.C.

H anson, J.C.E. Lichtenberg, and S.E. Peters. 1995. O rganic versus conventional grain production in the mid-Atlantic: An economic and farming system overview. Dept. Agr. Resource Econ., U niv. Md., College Park, Working Paper 95-22.

$H$ anson, J.C., D.M. Johnson, S.E. Peters, and R.R. J anke. 1990. The profitability of sustainable agriculture on a representative grain farm in the mid-Atlantic region, 1981-89. N.E. J. Agr. Resource Econ. 19(2):90-98.

H arper, C.R. 1992. Issues in pesticide policy: D iscussion. Northeastern J. Agr. Resource Econ. 19(2): 96-97.

H arwood, J., R. H eifneer, K. Coble, J. Perry, and A. Somwaru. 1999. M anaging Risk in farming: Concepts, research, and analysis. USD A Econ. Res. Ser. M arket and $T$ rade E con. D iv. Agr. E conomic R pt. 774.

H odges, R.D. 1978. The case for biological agriculture. E cologist Q uarterly, summer: 122-143.

H odges, R.D. 1982. Agriculture and horticulture: the need for a more biological approach. Bio. Agr. H ort. 1(1):1-13.
Ikerd, J.E. 1990. Agriculture's search for sustainability and profitability. J. Soil Water Conservation 45(1):18-23.

I kerd, J.E. 1996. Sustaining the profitability of agriculture. Paper presented at the American Agricultural Economics Association Extension Pre-conference: The Economist's Role in Agricultural Sustainability Paradigm, San Antonio, T exas, 27 July 1996. 14 J uly 2000. «ttp:/ Lwww.ssu.missouri.edu/ faculty/ /I kerd/ papers/ aae-sasa.htm>.

King, L. 1991. A comparison of cropping systems managed conventionally or with reduced chemical input. $\mathrm{N}$ orth $\mathrm{C}$ arolina StateU niversity. SustainableAgr. R es. E du. Rpt. LS88-9.

Klonsky, K. and L. T ourte. 2000. Cost and return studies. $U$ niv. Calif., $D$ avis, $D$ ept of Agr. Resource Economics, D avis. 19 July 2000. \http:/ / www.aes.ucdavis.edu/ ex/ departments/D ep agri \& res ec.htm>.

Klonsky, K. and L. T ourte. 1998. O rganic agricultural production in the $U$ nited States: Debates and directions. Amer. J. Agr. Econ. 80(5):1119-1124.

Lohr, L. 1998. Implications of organic certification for market structureand trade. Amer. J. Agr. E con. 80(5): 1125-1129.

Lee, L.K. 1992. A perspective on the economic impacts of reducing agricultural chemical use. Amer. J. Alternative Agr. 7:82-88.

Lichtenberg, E. 1992. Alternative approaches to pesticide regulation. Northeastern J. Agr. Resource E con. 19(2): 8392.

L ockertz, W. 1989. Comparativelocal economic benefits of conventional al ternative cropping systems. Amer. J. AlternativeAgr. 4:75-83.

M adden, J.P. and P.F. O 'C onnell. 1990. LISA some early results. J. Soil Water Conservation 45(1):61-64.

National Research Council. 1986. Pesticide resistance: Strategies and tactics for management. National Academy Press, Wash., DC.

O ffice of T echnology Assessment. 1995. Biologically based technologies for pest control. Office Technol. Assessment, Wash., D.C.
Pritts, M. and J. Kovach. 1997. O rganic strawberry production systems.18 July 2000. <http:/ / www.fvs. cornell.edu/ Faculty/ php/ M arvin Pritts/ organic.html>.

Raterman, K. 1997. M arket overview '96: Contradictions propel industry growth. Natural Food Merchandiser. 28(1):2630.

Ray, D.E., B.C. English, R.L. White, R.M . Pendergrass, and M.G. Bhat. 1992. Economic impacts of sustainability on southern agriculture. In: L.A. Johnson (ed.). Enhancing the environmental quality of the T ennessee $V$ alley region through alternative farming practices. U niv. T enn. Ext. Bul. EC 1022-750-9/ 92.

Sabih, S. F. and L.B.B. Baker. 2000. Alternative financing in agriculture: $A$ case for the CSA method. Acta H ort. 524:141148.

Scaller, N. 1988. Alternative agriculture gainsattention. Agricultural O utlook 1988. U SD A, Wash., D.C.

Smolik, J.D., T.L. D obbs, and D.H . Ricker. 1995. The relative sustainability of alternative, conventional, and reduced-till farming systems. Amer. J. Alternative Agr. $10(1): 25-35$

Temple, S. 1991. A comparison of conventional, low input and organic farmingThe transition phase and long term viability. U niv. C alif. Sustainable Agr. Res. E du. Rpt. LS89-18.

U.S. D epartment of Agriculture, 2000. Census of Agriculture. $\mathrm{N}$ ational Agricultural Statistics Service. 14 July 2000. \http:/ / www. nass.usda.gov/ census/>.

U.S. General Accounting Office. 1991. Pesticides: EPA could do more to minimize groundwater contamination $\mathrm{GAO} /$ RCED-91-75. U.S. G ovt. Printing O ffice, Wash., D.C.

Van En, R., L. M anes, and C. Roth. 1999. What is community supported agriculture and how does it work? 16 July 2000. $<$ http:/ / www.umass.edu/ umext/ csa/ about.html>.

Williams, J.R. 1990. Social traps and incentives: I mplications for low-input, sustainable agriculture. J. Soil Water Conservation $45(1): 28-30$. 